\title{
AS DIMENSÕES SOCIAIS DA MUDANÇA EM PEÇAS DE TEATRO DE AUTORES GAÚCHOS: UMA CONTRIBUIÇÃO PARA O ESTUDO DA INSERÇÃO E DA PROPAGAÇÃO DO PRONOME A GENTE NO PORTUGUÊS BRASILEIRO
}

\author{
Paulo Ricardo Silveira Borges \\ Submetido em 29 de abril de 2019. \\ Aceito para publicação em 23 de setembro de 2019. \\ Cadernos do IL, Porto Alegre, n. ${ }^{\circ}$ 59, outubro. p. 71-88.
}

POLÍTICA DE DIREITO AUTORAL

Autores que publicam nesta revista concordam com os seguintes termos:

Os autores mantêm os direitos autorais e concedem à revista o direito de primeira publicação, com o trabalho simultaneamente licenciado sob a Creative Commons Attribution License, permitindo o compartilhamento do trabalho com reconhecimento da autoria do trabalho e publicação inicial nesta revista.

Os autores têm autorização para assumir contratos adicionais separadamente, para distribuição não exclusiva da versão do trabalho publicada nesta revista (ex.: publicar em repositório institucional ou como capítulo de livro), com reconhecimento de autoria e publicação inicial nesta revista.

Os autores têm permissão e são estimulados a publicar e distribuir seu trabalho online (ex.: em repositórios institucionais ou na sua página pessoal) a qualquer ponto antes ou durante o processo editorial, já que isso pode gerar alterações produtivas, bem como aumentar o impacto e a citação do trabalho publicado.

Os autores estão conscientes de que a revista não se responsabiliza pela solicitação ou pelo pagamento de direitos autorais referentes às imagens incorporadas ao artigo. A obtenção de autorização para a publicação de imagens, de autoria do próprio autor do artigo ou de terceiros, é de responsabilidade do autor. Por esta razão, para todos os artigos que contenham imagens, o autor deve ter uma autorização do uso da imagem, sem qualquer ônus financeiro para os Cadernos do IL.

\section{POLÍTICA DE ACESSO LIVRE}

Esta revista oferece acesso livre imediato ao seu conteúdo, seguindo o princípio de que disponibilizar gratuitamente o conhecimento científico ao público proporciona sua democratização.

http://seer.ufrgs.br/cadernosdoil/index

Terça-feira, 29 de outubro de 2019. 


\title{
AS DIMENSÕES SOCIAIS DA MUDANÇA EM PEÇAS DE TEATRO DE AUTORES GAÚCHOS: UMA CONTRIBUIÇÃO PARA O ESTUDO DA INSERÇÃO E DA PROPAGAÇÃO DO PRONOME A GENTE NO PORTUGUÊS BRASILEIRO
}

\author{
THE SOCIAL DIMENSIONS OF THE CHANGE IN \\ THEATER PLAYS WRITTEN BY AUTHORS FROM THE \\ STATE OF RIO GRANDE DO SUL: A CONTRIBUTION \\ TO THE STUDY OF THE INSERTION AND \\ PROPAGATIONOF THE PRONOUN A GENTE IN \\ BRAZILIAN PORTUGUESE
}

Paulo Ricardo Silveira Borges

\begin{abstract}
RESUMO: $O$ objetivo deste artigo é demonstrar o quanto e como as variáveis sociais são importantes para a compreensão do processo de mudança em torno da inserção do pronome a gente no português brasileiro. O trabalho é na perspectiva da sociolinguística histórica, e os dados foram coletados em onze peças de teatro escritas por autores gaúchos, correspondendo a um período histórico de cem anos: 1896 a 1995.O trabalho procura colaborar para a compreensão da inserção do pronome a gente no português brasileiro a partir da análise de dados de peças de teatro do Rio Grande do Sul e verificar como as variáveis sociais se correlacionaram com as variáveis linguísticas durante o processo de mudança ocorrido.
\end{abstract}

PALAVRAS-CHAVE: português do Brasil; pronomes a gente vs. nós; variação e mudança; sociolinguística histórica.

\begin{abstract}
The purpose of this article is to demonstrate how much and how the social variables are important to the understanding of the process of change around the insertion of the pronoun a gente in Brazilian Portuguese. The work is in the perspective of historical sociolinguistics, and the data was collected in eleven theater plays written by authors from the state of Rio Grande do Sul, Brazil authors, corresponding to a historical period of one hundred years: 1896 to 1995.The work seeks to contribute to the understanding of the insertion of the pronoun a gente in Brazilian Portuguese from the data analysis of plays of Rio Grande do Sul and to verify how the social variables correlated with the linguistic variables during the process of change occurred.
\end{abstract}

KEYWORDS: Brazilian Portuguese; pronouns a gente vs. nós; variation and change; social variables; historical sociolinguistics.

\section{Introdução}

\footnotetext{
* Professor Associado da Universidade Federal de Pelotas. Possui doutorado e pós-doutorado pela Universidade Federal do Rio Grande do Sul.paulorsborges@gmail.com.
} 
Neste artigo, analisamos como ocorreu a inserção do pronome a gente no português brasileiro, com o objetivo de identificar o percurso histórico da mudança e de verificar as implicações linguísticas decorrentes da atuação das variáveis sociais gênero, faixa etária e classe social no processo histórico de variação e mudança referente à introdução da forma inovadora $a$ gente no quadro dos pronomes pessoais no português.

A amostra trabalhada é composta por onze peças de teatro de autores gaúchos ${ }^{1}$, correspondendo a um período histórico de cem anos: 1896 a 1995. Os textos analisados privilegiam o diálogo como forma de contemplar as características e as variáveis sociais dos personagens. Nosso objetivo é investigar como se propagou a mudança nos textos de teatro, dando-se ênfase para a forma expressa do pronome a gente em variação com o pronome nós.

O trabalho apresenta as concepções teóricas sobre variação e mudança linguística, considerando os fatores extralinguísticos ou sociais correlacionados, além de um referencial teórico sobre as dimensões sociais da mudança linguística na perspectiva de sua difusão e das evidências social, histórica e linguística, conforme postulado por Labov (1966), Weinreich, Labov e Herzog (1968),Kroch (1978) e Guy (2001). Apresentamos também a amostra analisada, os fatores sociais envolvidos na análise dos dados e os resultados da análise em tempo real das etapas da mudança em progresso, conforme o período analisado, além das considerações finais advindas da análise proposta.

\title{
2 Concepções teóricas sobre variação e mudança linguística
}

O estágio sincrônico da língua é resultado de um desenvolvimento passado que continua no presente. Uma análise que correlacione resultados de 'tempo aparente' (apparent time) com 'tempo real' (real time), a partir de uma dimensão histórico-social, poderá evidenciar os processos e os estágios pelos quais passaram e se encontram determinadas mudanças linguísticas. Paiva e Duarte (2003, p. 182), com relação à importância dos estudos de mudança na perspectiva de análise em tempo real, destacam que:

\begin{abstract}
Trata-se de um recurso imprescindível não apenas para identificar o momento do aparecimento ou morte de determinada variante linguística como também para verificar a regularidade na ação dos princípios que regem a variação e subjazem à implementação da mudança (PAIVA e DUARTE, 2003, p. 182).
\end{abstract}

Labov (1994, p. 26) entende que o objetivo principal da utilização de dados diacrônicos "é poder determinar o que ocorreu na história de uma língua ou de uma família linguística", levando-se em conta os aspectos sociais que contribuíram para o desenvolvimento de determinadas mudanças. Ao postularem uma teoria para a mudança linguística, Weinreich, Labov e Herzog (1968, p. 188) enfatizam que "nem toda a variabilidade e heterogeneidade na estrutura linguística envolve mudanças, mas toda mudança envolve variabilidade e heterogeneidade". Observa-se, assim, que as mudanças em progresso estão atreladas a uma concepção variacionista de linguagem,

\footnotetext{
${ }^{1}$ O termo "gaúcho" corresponde a uma denominação dada às pessoas nascidas e moradoras no Estado do Rio Grande do Sul, Brasil.
} 
compreendendo processos associados e covariados, haja vista que as mudanças não são instantâneas nem uniformes. A perspectiva diacrônica, nesse aspecto, complementa a análise sociolinguística.

Com o objetivo de melhor caracterizar o processo de mudança linguística, Weinreich, Labov e Herzog (1968) propõem um modelo que seja capaz de sistematizar a heterogeneidade da língua. A variação passa a ser entendida como uma característica própria da estrutura linguística, ou seja, algo possível de ser sistematizado. Os autores, a partir do componente social da linguagem e do aspecto relacionado a sua implementação (actuation), propõem as seguintes questões: "Que fatores podem ser considerados para a implementação das mudanças?" e "Por que as mudanças estruturais ocorrem em uma língua particular e em um determinado tempo, mas não em outros tempos?" (Weinreich; Labov; Herzog, 1968, p. 102).

Esses questionamentos serviram para impulsionar os estudos sociolinguísticos, com a concepção de que as comunidades de fala são caracterizadas por determinada heterogeneidade ordenada, diferentemente da noção de sistema homogêneo associado aos processos envolvendo mudança linguística. Nesse sentido, a sociolinguística, através do conceito de 'mudança em progresso', abriu novas perspectivas para o estudo histórico-diacrônico. A língua passa, assim, a ser analisada com base na sua estrutura social, em função do seu caráter heterogêneo.

Labov (1972, p.160-161), ao tratar dos mecanismos de amplitude e propagação da mudança linguística, apresenta cinco questionamentos que, no entendimento do autor, são importantes para a compreensão da inter-relação entre as estruturas sociais e linguísticas: (1) Existe uma direção genérica na evolução linguística? (2) Quais são os determinantes universais da mudança linguística? (3) Quais são as causas do surgimento contínuo de novas mudanças linguísticas? (4) Quais são os mecanismos dessas mudanças? (5) A evolução linguística tem uma função adaptativa?

O próprio Labov (1972, p. 160-61), referindo-se aos problemas (problems) relacionados à mudança linguística apresentados por Weinreich, Labov e Herzog (1968, p. 101-102), entende que a resolução para essas questões passa por três pontos imprescindíveis: (a) problema da transição (transition problem): consiste em encontrar o caminho pelo qual uma mudança linguística evoluiu de uma etapa prévia para outra posterior; (b) problema do encaixamento (embedding problem): consiste em encontrar a matriz contínua do comportamento social e linguístico em que a mudança linguística se produz, isto é, investigar as correlações entre os elementos do sistema linguístico e entre o sistema linguístico e o sistema social; (c) problema da avaliação (evaluation problem): consiste em encontrar as correlações subjetivas ou latentes das mudanças objetivas ou manifestamente observadas, ou seja, correlacionar as atitudes gerais e as aspirações dos falantes em relação ao seu comportamento linguístico. As posições de Labov, ao aproximarem a Sociolinguística da Linguística Histórica, podem contemplar explicações relacionadas a aspectos históricos e sincrônicos, o que possibilita o melhor conhecimento dos fenômenos linguísticos no tempo real e, consequentemente, a melhor compreensão dos fenômenos na atualidade.

\section{As dimensões sociais da mudança linguística}


Deve-se ressaltar, inicialmente, a importância de se tratar variação e mudança de forma conjunta, uma vez que, sociolinguisticamente, são entendidas como dois aspectos de um mesmo modelo linguístico. A variação é, portanto, uma contraparte sincrônica da mudança. Elizaincín (1993, p. 264) destaca que o aspecto social de qualquer atividade humana, entre elas a linguística, é intrinsecamente histórico:

\begin{abstract}
Si la primacía de lo histórico está tan bien estabelecida y fundamentada, es relativamente fácil salir de ahí hacia el aspecto social del lenguaje, porque si bien la comprensión del problema del cambio no puede independizarse de la consideración del lenguaje en su contexto social, tampoco el enfoque social de la actividad lingüística puede escindirce de lo diacrónico: sea en el nivel microsociolingüístico como en el macro- las relaciones y funciones actuales que identificamos y estudiamos hoy no puedem entenderse sin referencia a lo histórico (ELIZAINCÍN, 1993, p. 264).
\end{abstract}

Um dos enfoques abordados no estudo de variação e mudança está relacionado com os aspectos que tratam das causas e da difusão das mudanças. Para Guy (2001), é possível investigar contextos linguísticos e sociais envolvendo variação e mudança, levando-se em conta a frequência de uso de determinado fenômeno, quem o usa e em que contextos é utilizado. Contudo, determinar o ponto de partida de uma mudança e o porquê de sua ocorrência torna-se algo bem mais complexo.

Deve-se levar em consideração que os limites da difusão de determinada mudança coincidem com os limites sociais e linguísticos dos próprios membros da comunidade envolvida. Esse fato também é referido por Lucchesi (2015, p. 36), ao analisar a polarização sociolinguística no Brasil e referir-se ao processo de nivelamento linguístico: "O valor social atribuído às variantes linguísticas afeta, por sua vez, os padrões coletivos de uso da língua. Completa-se, dessa forma, o circuito da relação dialética entre uso, avaliação e mudança linguística". Verifica-se, assim, que a evolução linguística e sua correlação com os estudos de mudanças ocorridas no passado torna-se uma das estratégias usadas para se verificar os diferentes estágios percorridos por determinado fenômeno linguístico variável.

O estudo da mudança em progresso, no entender de Guy et al. (1986, p. 30-33), tem sido metodologicamente desenvolvido a partir de três tipos de evidências: a social, a histórica e a linguística. Entre as dimensões associadas ao aspecto social, a idade seria uma das mais importantes, uma vez que vários estudos de mudança em progresso demonstram que falantes mais jovens tendem a usar mais as formas inovadoras do que falantes mais velhos. Mattos e Silva (2008, p. 11), nesse aspecto, frisa que "pelas frestas da variação etária se evidencia, na sincronia, a diacronia".

Especificamente à classe social, Guy (1987, p. 56-60) ressalta que esse fator também pode desempenhar um importante papel no surgimento das inovações linguísticas, que tendem a se difundir gradualmente através do espectro social. Um estudo sociolinguístico para analisar determinada mudança em progresso deverá, portanto, responder às seguintes questões: Que grupos sociais originam as mudanças? E qual é a motivação deles para fazê-las? As respostas às questões propostas envolvem avaliações complexas, pois os diferentes usos sociais da língua estão atrelados a classes sociais representativas e marcadoras de estilos e de identidades que constituem e marcam determinados grupos sociais. Salienta-se ainda o fato de alguns grupos sociais serem mais inovadores e aceitarem mais rapidamente determinadas formas inovadoras, enquanto outros tendem a resistir mais à mudança. Naro e Scherre (1991, p. 15), nesse particular, já enfatizaram que "o que está mudando para algumas pessoas pode estar 
estável para outras pessoas e o que está aumentando para alguns pode estar diminuindo para outros". A variação linguística, então, seria um reflexo da própria dinâmica social de determinada comunidade podendo, também, envolver mudança.

Os trabalhos de Labov (1966) e Kroch (1978), especialmente, são modelos importantes para a descrição da distribuição social de mudanças em andamento. $\mathrm{O}$ primeiro, de Labov (1966), mostra que as mudanças em progresso geralmente apresentam uma distribuição curvilínea, representando uma mudança do tipo espontânea. A inovação seria usada principalmente e com maior frequência pelo grupo intermediário na escala social (upper working and lower middle classes), que representaria o cume do gráfico de padrão curvilíneo. Esse tipo de distribuição incute a seguinte questão: por que mudar e quem possui motivação social para a mudança?

O segundo, de Kroch (1978), enfatiza a distribuição linear, representada por uma correlação inversa entre status social e utilização de determinada forma inovadora. Haveria, inicialmente, uma resistência à mudança pelos grupos de status mais alto (highest status groups).Nesse caso, uma outra questão poderia ser proposta: aceitandose o fato de que historicamente todas as línguas mudam durante todo o tempo, por que certas pessoas, de determinados grupos sociais, resistem a determinadas mudanças?Ambos os modelos indicam que mudanças espontâneas geralmente não são iniciadas pela classe mais alta, mas pela classe que depende mais da comunidade para adquirir prestígio. Assim, fica evidente o fato de que existe uma correlação entre mudança linguística e a posição (status) de determinados grupos na sociedade.

No que diz respeito ao gênero, trabalhos sociolinguísticos têm demonstrado que as mulheres, frequentemente, lideram as mudanças. A própria caracterização da construção social da variável sexo vem merecendo maior atenção, uma vez que a noção de gênero pode ser mais produtiva para o entendimento da correlação do sexo com as variáveis linguísticas. Deve-se destacar que as dimensões de idade, classe social e gênero não são, separadamente, variáveis suficientes e conclusivas para o entendimento de um processo de mudança em progresso, mas uma constelação particular de fatores em conjunção com outros pontos que, somados, constituem evidências consistentes para melhor avaliarem os caminhos percorridos por determinada mudança.

A segunda evidência, além da social, para o estudo da mudança linguística, é a histórica. Guy et al. (1986, p. 33) entendem que a análise em 'tempo real' permite que se tenha informações sobre o estágio inicial de determinada mudança. Esse tipo de evidência, entretanto, deve ser cuidadosamente considerada para determinados tipos de mudança, como as mudanças fonéticas/fonológicas, por exemplo, já que as fontes para análise são escassas e, na maioria dos casos, não existem.

No caso específico deste trabalho, mostraremos evidências histórico-sociais relacionadas ao comportamento da forma a gente no português gaúcho, em variação com a forma nós, no decorrer de 100 anos (1896 até 1995), período no qual ocorreu um processo de pronominalização ${ }^{2}$ da forma a gente com base em aspectos semânticoreferenciais associados a sua efetivação como pronome pessoal. Romaine (1982, p. 25), ao tratar da variação diacrônica na perspectiva da sociolinguística, destaca a importância da utilização de textos históricos para a análise da mudança linguística, enfatizando que os resultados desse tipo de análise são "relevantes para os modelos de mudança histórica

\footnotetext{
${ }^{2}$ Esse processo tem sido referido como pronominalização (cf. Omena, 1986), gramaticalização (cf. Menon, 1996; Omena e Braga, 1996; Lopes, 1999; Zilles, 2002, 2003) ou pessoalização (cf. Borges, 2004). Utilizaremos aqui o termo pronominalização.
} 
em geral e podem lançar alguma luz sobre a relação entre a variação sincrônica e o mecanismo de mudança linguística".

Como terceira evidência, somando-se às evidências social e histórica, Guy et al. (1986, p. 33) apresentam a evidência linguística. Os autores partem do pressuposto que a distribuição linguística de uma suposta inovação se estende por vários contextos condicionantes. Alguns ambientes seriam mais favoráveis e as mudanças aconteceriam primeiramente neles, enquanto outros seriam menos favoráveis e as mudanças ocorreriam mais tarde. No entanto, é necessário (a) definir quais contextos são mais favoráveis, (b) estabelecer como que as mudanças principiam e (c) definir os meios para identificar a variação sociolinguística estável originária de mudança em progresso.

Para o estudo dos fenômenos linguísticos e, em especial, para os objetivos deste trabalho, as evidências sociais merecerão atenção especial, uma vez que estão intrinsecamente associadas ao tipo de análise aqui proposta.

\section{Os critérios para a escolha das obras: textos de teatro de autores gaúchos - 1896 até 1995}

Trataremos aqui da utilização da forma a gente em onze peças de teatro de autores gaúchos, abrangendo um período de cem anos, que se estende de 1896 até 1995 , com intervalos de dez anos entre uma obra e outra. A escolha do final do século XIX (1896), para servir como ponto de partida para as obras que compõem o corpus diacrônico aqui utilizado, deve-se principalmente a dois fatores: o primeiro diz respeito à própria formação histórica do Rio Grande do Sul, uma vez que foi a partir de 1830 que as atividades culturais como a imprensa, a literatura e as artes teatrais começaram a florescer, principalmente nos grandes centros como Porto Alegre, Rio Grande e Pelotas, estendendo-se também por outras cidades da campanha e fronteira ${ }^{3}$. Autores como Qorpo Santo (1829-1883), Caldre e Fião (1824-1876), Apolinário Porto Alegre (18441904), Taveira Júnior (1836-1892) e Simões Lopes (1865-1916) começaram, principalmente na segunda metade do século XIX, a desenvolver uma literatura associada ao cotidiano da sociedade gaúcha daquela época. ${ }^{4}$ As características próprias ao comportamento social dos gaúchos, como também a valorização do aspecto regional associado ao homem "rurbano", começam a ser valorizadas e transportadas para as obras literárias dos autores citados, principalmente no que se refere ao teatro.

A peça A Viúva Pitorra, de Simões Lopes Neto, que corresponde ao final do século XIX, está incluída no corpus organizado para este trabalho representando bem as características cotidianas da época: ambiente provinciano, burguesia atrelada à cultura europeia, relacionamentos amorosos com fins econômicos, excessiva valorização dos sinais exteriores característicos da "situação de luto", vigilância da sociedade sobre os atos da viúva, dogmas atrelados a determinados assuntos (como sexo), etc. Nesse

\footnotetext{
${ }^{3}$ O termo "campanha" caracteriza aqui cidades do interior do RS como Bagé, Rio Pardo, Cachoeira do Sul, Piratini, etc.; o termo "fronteira" caracteriza aqui cidades do RS fronteiriças com o Uruguai e a Argentina como Jaguarão, Santana do Livramento, Uruguaiana e São Borja.

${ }^{4}$ Veja-se, nesse aspecto, a obra de HESSEL, Lothar. O teatro no Rio Grande do Sul. Porto Alegre: Editora da UFRGS, 1999.

5 O termo "rurbano" é utilizado para caracterizar os fortes laços do homem urbano daquela época com o meio rural. Deve-se enfatizar que a base da economia gaúcha de então estava na pecuária. Conforme Bortoni-Ricardo (2009, p. 53), a variedade "rurbana" é "formada pelos migrantes de origem rural que preservam muito de seus antecedentes culturais, principalmente no seu repertório linguístico".
} 
sentido, acredita-se que a linguagem utilizada pelas pessoas, nas suas diferentes situações de uso, em maior ou menor grau, também esteja representada nos diferentes diálogos encontrados nesta e nas demais peças de teatro analisadas.

O segundo fator para a escolha do final do século XIX (1896) como ponto de partida para as obras que compõem o corpus diacrônico organizado e utilizado neste trabalho, está relacionado aos estudos linguísticos já realizados sobre o uso de a gente e como se deu esse processo de mudança em tempo real. ${ }^{6}$ Nesse aspecto, o trabalho de Lopes (1999), sobre "A inserção de a gente no quadro pronominal do português: percurso histórico", serve como referência para o estabelecimento do período inicial (segunda metade do século XIX) do corpus diacrônico a ser analisado para se alcançar os objetivos aqui propostos. A autora, utilizando-se de dados retirados de textos do século XIII ao século XX, busca caracterizar a inserção de a gente no sistema dos pronomes do português. A partir dessa análise, conclui que:

O processo de pronominalização do substantivo gente foi lento e gradual, uma vez que só foram localizadas ocorrências de a gente como pronome na segunda metade do século XVIII. Antes disso, mais precisamente entre o século XVI e a primeira metade do século XIX, há exemplos esporádicos em que a forma $a$ gente apresenta ambiguidade interpretativa, ou seja, tanto pode ser considerada sinônimo de "pessoas" quanto variante de nós (LOPES, 1999, p. 72).

Do mesmo modo, como se configura a intensificação do emprego de a gente como forma pronominal do século XIX em diante, a interpretação ambígua deixa de se fazer presente (LOPES, 1999, p. 74).

Levando-se em conta estas constatações, justifica-se a escolha do final do século XIX como relevante para a identificação do processo de mudança em torno da inserção do pronome a gente no português, bem como para a verificação dos componentes sociais presentes no processo de mudança ocorridos nas peças de teatro analisadas, correspondendo a um corpus diacrônico relacionado a um período histórico de 100 anos.

Os textos selecionados buscam refletir, da melhor forma possível, o cotidiano de determinadas pessoas e grupos através de seus costumes. Um dos objetivos da escolha do teatro, e mais especificamente de peças que refletissem o cotidiano das pessoas, foi poder representar a linguagem mais informal utilizada pelas pessoas comuns em seus afazeres cotidianos, aproximando-se o máximo possível do vernáculo. ${ }^{7}$

As peças de teatro são textos escritos para serem falados, supostamente mais próximos da fala efetivamente produzida ou, pelo menos, distinto dos outros gêneros como o narrativo, por exemplo, que são produzidos para serem lidos. Deu-se especial atenção, portanto, para obras em que a comicidade estivesse presente nos diálogos, caracterizando o que se chama de "comédia de costumes", para tentar traçar o percurso

\footnotetext{
${ }^{6}$ Referido aqui como o desenvolvimento na evolução linguística num período de tempo, a partir da comparação do comportamento linguístico de falantes e/ou personagens em dois (ou mais) momentos temporais distintos, diferentemente do tempo aparente em que se estuda os fenômenos variáveis num determinado momento e nas diferentes faixas etárias.

${ }^{7}$ O termo "vernáculo" é referido aqui no sentido sociolinguístico de sua utilização, ou seja, a língua utilizada em uma situação cotidiana de comunicação. Por extensão, linguagem presente nas narrativas de experiência pessoal.

${ }^{8}$ Comédia que traz a sátira de certos costumes, tipos sociais ou intrigas do cotidiano. Gênero teatral com ênfase na caricatura de tipos sociais e na crítica dos costumes de determinada época.
} 
do uso da forma a gente no Rio Grande do Sul. As peças de teatro, especialmente as comédias, podem constituir um importante corpus para os estudos linguísticos, uma vez que os diálogos tendem a recriar, em maior ou menor grau, a linguagem cotidiana das pessoas.

As obras foram detalhadamente selecionadas segundo critérios específicos próprios ao tipo de análise aqui proposta. A escolha de autores do sexo masculino, por exemplo, explica-se pela escassez e/ou pouca divulgação de autoras na literatura do século XIX e início do século XX, em especial no que se refere ao teatro. Mesmo admitindo que autores masculinos e femininos possam recriar, de modo distinto (em consonância com suas práticas sociais e com a percepção dessas mesmas práticas), determinadas diferenciações sociolinguísticas em suas obras, ao darem voz a seus personagens (como fez Gil Vicente, por exemplo), optou-se por textos de autores masculinos. Essa opção procurou viabilizar uma primeira análise sob a perspectiva temporal em materiais produzidos no (e para o) Rio Grande do Sul, por autores locais; certamente, ela não exclui futuras análises em que essas questões sejam contempladas de modo mais abrangente.

A classe social dos escritores também poderia ser um fator diferenciador na criação da linguagem dos personagens. Todos os autores selecionados têm grau de escolaridade acima do médio, muitos dos quais com cursos universitários. Os escritores das peças de teatro analisadas aqui pertencem a uma camada culturalmente privilegiada. Essa condição dificilmente poderia ser diferente, uma vez que, principalmente no final do século XIX e início do século XX, somente um número reduzido de pessoas, pertencentes à elite social, tinha acesso à educação formal. Esse fato, contudo, não impede que os escritores, pelo menos alguns, percebam e recriem as diferenças de linguagem entre pessoas pertencentes a camadas sociais distintas, uma vez que a ampliação das experiências culturais pode, em muitos casos, favorecer a percepção de determinadas variações e/ou mudanças linguísticas em curso. $\mathrm{O}$ exemplo a seguir, retirado da peça A ponte, de 1962, mostra bem determinadas características sociais dos personagens:

(1) Mãe - O quê? Tu escreveu sobre a gente no jornal? Desgraçado! Agora vai dar pra aparecer aquelas gentes do serviço social e nós vai terminar por ter que dar o fora daqui! Por que se mete no que não é da tua conta? (Ruzicki, 1962 , p. 21$)^{9}$

Outros dois aspectos também mereceram cuidado especial quando da escolha das obras: o primeiro referente ao tamanho das obras, em número de páginas, uma vez que peças muito curtas restringiriam as chances de ocorrência de a gente. Das onze obras analisadas, o número mínimo de páginas foi de vinte e nove e o máximo de cento e trinta e três. A média das onze peças ficou em sessenta e oito páginas, um número considerado satisfatório para a análise aqui proposta; o segundo aspecto diz respeito ao número de personagens presentes nas peças. Obras monologadas, ou que tivessem um número reduzido de personagens, dificilmente representariam as diversas classes sociais e suas manifestações linguísticas, o que diminuiria a possibilidade de ocorrerem variações associadas ao componente social. ${ }^{10}$ Em alguns casos analisou-se um conjunto

\footnotetext{
${ }^{9}$ RUZICKI, Valdir. A ponte: peça em 8 cenas. Porto Alegre: Livraria do Globo, 1962.

${ }^{10}$ Levando-se em conta um dos princípios básicos da sociolinguística de que as variáveis de ordem social influenciam na escolha das variantes.
} 
de pequenas peças, com um número reduzido de personagens em cada uma delas. Entretanto, no conjunto, os personagens cobriam um amplo espectro de diferentes realidades sociais.

\section{A análise dos dados: o uso do pronome a gente nas peças de teatro}

Para facilitar a leitura dos resultados, o Quadro 1 traz o conjunto de obras utilizadas, bem como as décadas e o número de ocorrências equivalentes a cada uma das peças:

Quadro 1 - Décadas e número total de ocorrências das formas nós e a gente correspondentes a cada uma das onze obras analisadas

\begin{tabular}{|c|c|c|}
\hline Obra / autor / ano & Década & $\begin{array}{c}\text { Número } \\
\text { ocorrências }\end{array}$ \\
\hline 1 - A Viúva Pitorra (Simões Lopes Neto) - 1896 & 1890 & 31 \\
\hline $2-$ A ciumenta velha (Joaquim Alves Torres) - 1905 & 1900 & 16 \\
\hline 3 - Nossa terra (Abadie Faria-Rosa) - 1917 & 1910 & 72 \\
\hline $\begin{array}{l}\text { 4 - Adão, Eva e outros membros da família (Álvaro Moreira) - } \\
1927\end{array}$ & 1920 & 48 \\
\hline 5 - Iaiá Boneca (Ernani Fornari) - 1938 & 1930 & 52 \\
\hline $\begin{array}{l}\text { 6-Seis anos de rádio: história anedótica de Pery\&Estellita } \\
\text { (Pery Borges) - } 1942\end{array}$ & 1940 & 74 \\
\hline 7 - Quando elas queres (Paulo Hecker Filho) - 1958 & 1950 & 83 \\
\hline 8 - A ponte (Valdir Ruzicki) - 1962 & 1960 & 145 \\
\hline $\begin{array}{l}\text { 9-Pode ser que seja só o leiteiro lá fora (Caio Fernando } \\
\text { Abreu) }-1974\end{array}$ & 1970 & 70 \\
\hline $\begin{array}{l}\text { 10-Bye,byesweet home! A barra do tribunal, Casinha } \\
\text { pequenina, Tudo no divã (Ivo Bender) - } 1983\end{array}$ & 1980 & 20 \\
\hline $11-$ A coisa certa (Júlio Conte) -1995 & 1990 & 101 \\
\hline
\end{tabular}

$\mathrm{Na}$ análise das peças, foi encontrado um total de 712 ocorrências de nós e $a$ gente. Os dados foram computados levando-se em conta as variantes selecionadas, as ocorrências encontradas nas onze peças de teatro, o número de ocorrências e os percentuais atribuídos a cada uma das formas utilizadas pelos personagens.

É necessário salientar que o total de 712 ocorrências representa a presença das formas nós e a gente (expressas e não-expressas) em todas as funções sintáticas possíveis. A Tabela 1mostra o número de ocorrências e os percentuais referentes à utilização das formas variáveis para a primeira pessoa do plural. 
Tabela 1 - Frequência do uso de nós e a gente (expressos e não-expressos) nas onze peças de teatro analisadas

\begin{tabular}{c|c|c|c|c|c}
\hline \multirow{2}{*}{ Formas nós e a gente } & Nós & a gente & $\phi$ nós & $\phi$ a gente & Totais \\
\cline { 2 - 6 } & $\mathrm{n} / \%$ & $\mathrm{n} / \%$ & $\mathrm{n} / \%$ & $\mathrm{n} / \%$ & $\mathrm{n} / \%$ \\
\hline Totais & $189 / 26,5$ & $162 / 22,8$ & $354 / 49,7$ & $7 / 1$ & $712 / 100$ \\
\hline
\end{tabular}

Considerando-se apenas as ocorrências dos pronomes a gente e nós "expressos", o percentual de uso de a gente passa para $46 \%$, exatamente o dobro do verificado anteriormente. Para esta análise, utilizaremos apenas os dados de nós e a gente expressos especificamente em relação à função de sujeito. Verificou-se um total de 246 ocorrências de nós e a gente expressos, assim distribuídas: 122 de nós $(=49,6 \%)$ e de 124 de $a$ gente $(=50,4 \%)$. Os resultados demonstram uma forte presença do pronome $a$ gente na função de sujeito, indicando uma mudança substancial decorrente do processo de variação. O Gráfico 1 apresenta os percentuais para a forma pronominal a gente, em variação com a forma nós, especificamente em função de sujeito, para as décadas referentes às onze peças de teatro analisadas.

\section{Gráfico 1 - Percentual de uso de a gente expresso, em função de sujeito, comparativamente com nós, nas onze peças de teatro analisadas}

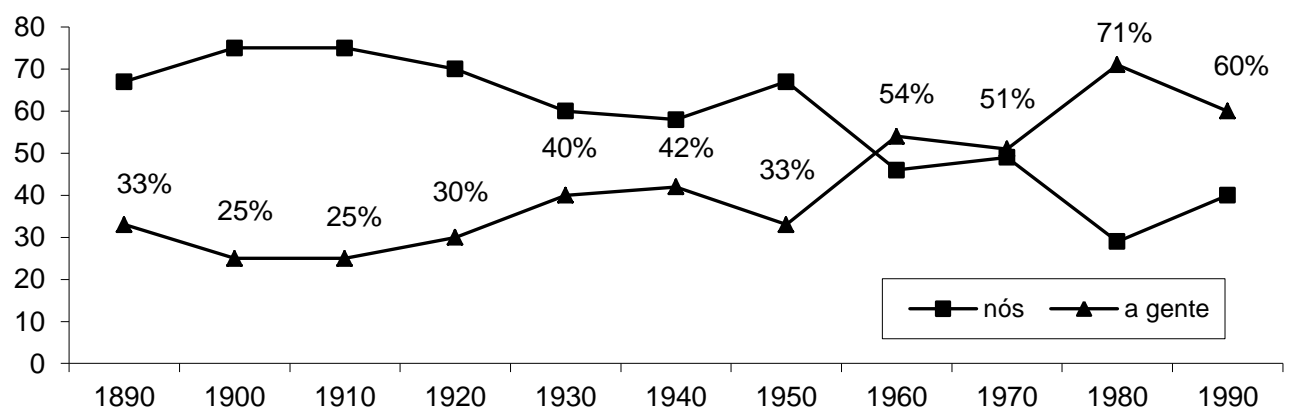

Fonte: Borges, 2004

Evidencia-se, pelos resultados, uma efetiva introdução da forma a gente, em variação com a forma nós, no sistema pronominal do português gaúcho, principalmente a partir da década de 1960. O uso de a gente expresso, na primeira metade do século XX, ficou com um percentual médio de 32\%. A partir da década de 1960 a curva ascendente fica mais pronunciada, deixando clara a competição entre as formas nós vs. a gente, como também a aceleração do processo que, dadas as proporções, a direção e as evidências já registradas na literatura, se configura como mudança em curso. Da década de 1960 em diante, a forma a gente expressa tem sempre percentual superior a 50\%, bem acima dos percentuais das décadas anteriores, superando também a forma nós.

Esses dados poderiam sugerir que a utilização de a gente é um fenômeno relativamente novo no português brasileiro, mas o registro dessa forma como 
característica da linguagem rural e popular, nos trabalhos de dialetologistas (Amaral, 1955, p. 73-74) e Nascentes (1953, p. 170), referentes à primeira metade do século XX, nos faz pensar que essa seria uma conclusão apressada.

Outros aspectos, linguísticos, históricos e sociais, também merecem destaque: (1) Lopes $(1999$, p. 131) mostra que o percurso histórico da pronominalização de $a$ gente começou nos séculos XVIII e XIX, tendo se efetivado no século XX. Entretanto, não especifica em que período do século $\mathrm{XX}$ a gente intensificou-se com referência determinada; (2) A questão demográfica, em especial o êxodo rural, poderia ter contribuído para este processo? A forma a gente, supondo-se que já existisse no campo (zona rural), foi então levada para a cidade? Tem-se alguma informação sobre isso no Rio Grande do Sul? E na cidade, era usada pelas classes mais baixas até os anos 60/70, quando passou a ser utilizada também pelas classes médias, provocando a aceleração da mudança? As respostas a estas perguntas não são fáceis de serem encontradas, mas considerá-las é importante para não se tirar conclusões apressadas sobre os fatores sociais que interferiram para a efetivação do uso de a gente; (3) $\mathrm{O}$ fato de se estar analisando peças de teatro (de autores escolarizados) afetaria os resultados? Acreditando-se que as peças são um meio indireto de observar o que está ocorrendo na fala, pode-se pensar que haja um descompasso entre a forma utilizada na escrita e a forma utilizada na fala, no sentido de que é possível que demore um tempo até que a forma usada na fala apareça no texto escrito, mesmo que seja texto de teatro.

Portanto, parece adequado supor que as formas inovadoras apareçam antes neste tipo de texto do que em outros, como os textos informativos, administrativos e acadêmicos, por exemplo, o que justifica trabalhar com o teatro como a melhor aproximação indireta da fala cotidiana, ao lado das cartas pessoais e informais. Se existe um descompasso neste caso, tem-se de concluir que a mudança já estivesse em curso na oralidade, talvez desde o século XIX, e que seu registro em contextos de fala, em grande escala, só ocorreu a partir dos anos 1960/1970, devido às condições sociais determinantes e representativas desse período histórico no Brasil.

Um estudo mais detalhado dessas condições sociais teria que ser realizado, levando-se em conta os registros históricos de então e outros aspectos relevantes, como a formação da classe trabalhadora ligada à indústria, o trabalhismo, a promoção de leis sociais, o êxodo rural, etc.; nos anos 60 , no Rio Grande do Sul, a legalidade, a revolução de 64, a repressão; nos anos 70, o movimento hippie, a contracultura, o feminismo, etc. Todos esses componentes, associados a outros fatores sociais que contribuíram para a constituição histórico-linguística da sociedade gaúcha, mereceriam atenção especial, uma vez que poderiam, em uma escala maior ou menor, estar associados com a efetivação e uso da forma a gente como pronome pessoal no português brasileiro.

É interessante enfatizar que os resultados de diferentes estudos de fala, com dados coletados a partir da década de 1980, mostram que o uso de a gente vem aumentando muito nos últimos anos, principalmente nos grandes centros urbanos. Observe-se, por exemplo, os percentuais de uso para a forma a gente: Omena (1986), dados de Rio do Janeiro, com 69\%; Borba (1993), dados de Curitiba, com 64\%; Zilles (2002), dados de Porto Alegre, com 70\%; Seara (2000), dados de Florianópolis, com 72\%; Borges (2004), dados de Pelotas, com 78\%, e dados de Jaguarão, com 69\%. Nesse particular, Omena (1996, p. 315), ao tratar das influências sociais na variação entre nós e a gente, mais especificamente sobre o cruzamento da idade e sexo associado à forma nós, verificou uma diminuição abrupta, para ambos os gêneros, da forma nós, entre as gerações de 15/25 anos e 26/49 anos, como também entre os homens de 26/49 anos e 
50/71 anos. E acrescenta: "Tudo se passa como se tivesse havido uma causa, antes de 1930, para a substituição de nóspora gente, que parece ter-se exacerbado na década de 1960". Deve-se referir que é justamente entre as décadas de 1960 e de 1970 que se acentua o êxodo rural no Brasil. Nesse período, a população, até então predominantemente rural, passa a caracterizar-se como uma população efetivamente urbana. $^{11}$

Omena utiliza "parece" porque não se tinha, até então, trabalhos relacionados à utilização de a gente em tempo real e porque valeu-se da metodologia de tempo aparente. Parece que os dados aqui apresentados sustentam essa hipótese, uma vez que, observando-se o corpus utilizado, foi realmente nos anos sessenta que ocorreu o aumento na utilização da forma a gente (cf. Gráfico 1). Esse fato também poderia estar indicando que o processo já estaria em andamento na década de 1960, tendo se exacerbado no começo da década de 1970 e se tornado visível até mesmo em algumas peças de teatro.

Outro ponto a destacar, dos resultados do Gráfico 1 apresentado anteriormente, foi o percentual elevado de $33 \%$ de a gente encontrado na década de 1890, associada à obra A Viúva Pitorra, de Simões Lopes Neto. Sabe-se que Simões Lopes escreveu duas versões dessa peça (a primeira versão em 1896 e a segunda versão em 1898). Nesse particular, Heemann (2018, p. 23) enfatiza que:

\begin{abstract}
Os diálogos nas duas Viúvas Pitorras mudam bastante de um para outro texto. Não no sentido de alterar a situação, os personagens ou os incidentes, mas nas expressões e frases com que réplicas e frases aparecem compostas. Cada uma das versões apresenta maneiras e redações diversas de fazer o personagem expressar-se em suas falas. Como se o autor experimentasse ditos na busca da frase mais apropriada. (...) O autor como que deixou a diversidade das versões para que um encenador fizesse escolhas. (HEEMANN, 2018, p. 23)
\end{abstract}

As alterações nas expressões e frases utilizadas pelos autores ressaltam o cuidado que o autor dispensou para as questões linguísticas. ${ }^{12} \mathrm{O}$ fato de o autor preocupar-se com os aspectos linguísticos pode ter sido um elemento diferenciador no que se refere ao percentual elevado de $33 \%$, associado àquela década, atribuído à presença da forma expressa a gente. Outros fatores, como estilísticos, regionais e sociais também poderiam estar contribuindo para essa diferenciação. No entanto, torna-se difícil fazer uma avaliação sobre os mesmos, uma vez que outros campos associados à análise linguística e/ou literária teriam que ser enfocados, o que escapa aos propósitos desta análise.

\title{
6 As variáveis sociais e o uso de a gente nas peças de teatro
}

Os percentuais e pesos relativos para o uso de a gente nas onze peças de teatro de autores gaúchos, quanto às variáveis sociais gênero, faixa etária e classe social constam do Quadro 2. Os resultados mostram que: (1) a forma inovadora a gente foi favorecida pelas personagens femininas, tanto em percentual (56\%) como em peso

\footnotetext{
${ }^{11}$ Conforme IBGE - Instituto Brasileiro de Geografia e Estatística: www. ibge.gov.br/censohistorico.

${ }^{12}$ Veja-se, nesse aspecto, a dissertação de mestrado de Mambrini (2004), que trata da "Colocação pronominal em duas versões de 'A viúva Pitorra', de Simões Lopes Neto".
} 
relativo $(0,56)^{13}$. Esses valores são importantes, pois demonstram uma tendência verificada em diferentes trabalhos de sociolinguística, que conferem às mulheres $\mathrm{e}$ também aos jovens percentuais mais elevados na utilização de formas inovadoras (Labov, 1990, p. 239); (2) os personagens da faixa etária intermediária (de 26-49 anos) foram os que mais utilizaram a gente (53\% / 0,54). Em termos percentuais, os personagens com menos de 50 anos, independente da classe social, ficaram à frente no uso da forma a gente, configurando o que os estudos sociolinguísticos caracterizam como um processo de mudança em curso; (3) o uso de a gente é favorecido pelos personagens da classe baixa, com percentual de $54 \%$ e peso relativo de 0,56 , seguido pela classe média-baixa com percentual de $51 \%$ e peso relativo de 0,48 ; a classe baixa, portanto, aparece como impulsionadora da forma inovadora.

Quanto à variável gênero nas peças de teatro, os resultados refletem o que também foi encontrado em outros trabalhos em tempo aparente sobre o uso de a gente, como o de Seara (2000), Zilles (2002) e Borges (2004), nos quais também as mulheres apresentaram percentuais e pesos relativos superiores aos dos homens. Levando-se em conta que as mudanças implementadas pelas mulheres poderiam também indicar uma mudança do tipo espontânea, os resultados para o uso de a gente nas peças de teatro poderiam ainda ser um indício de avanço no uso de a gente nas gerações seguintes no português brasileiro. ${ }^{14}$

Quadro 2 - Uso de a gente expresso nas onze peças de teatro analisadas, conforme gênero, faixa etária e classe social

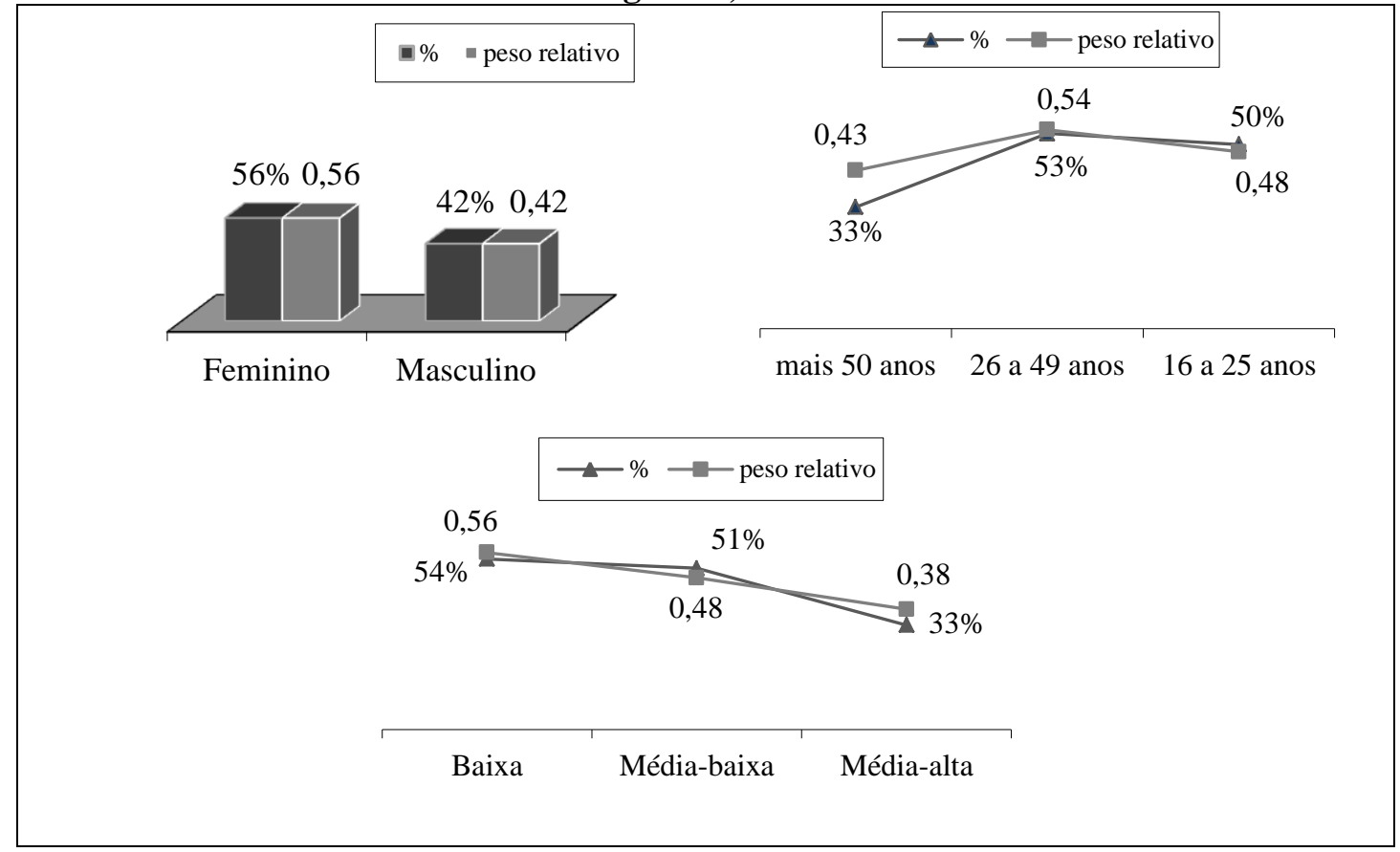

\footnotetext{
${ }^{13}$ Para os resultados estatísticos, utilizou-se o programa Varbwin: Varbrul através do windows.

${ }^{14}$ Conforme Princípio 4 apresentado por Labov (2001, p. 292): "Em mudança linguística vinda de baixo, as frequências de uso de formas inovadoras pelas mulheres são maiores que as dos homens".
} 
Resultados de diferentes análises em tempo aparente para o uso de a gente têm demonstrado que os falantes mais jovens são os que mais utilizam a forma inovadora, o que é compatível com um processo de mudança em curso. E é essa sintonia mais geral entre os dados sociais e linguísticos que sustenta fortemente a interpretação de mudança em curso. Nas peças de teatro, a forma inovadora parece ter menor prestígio (status) na classe média-alta, indicando uma certa estigmatização em relação ao seu uso. $O$ processo de mudança, nos textos de teatro, ocorreu 'de baixo para cima', haja vista que a classe baixa favoreceu o uso de a gente ${ }^{15}$ Oushiro $(2015$, p. 163), ao tratar da interação social entre gênero/faixa etária e classe social, destaca que "é na classe média, sobretudo na classe média baixa, que as diferenças de gênero se fazem mais presentes". Ressalta ainda que, dependendo do tipo de comunidade e de como se dá o encaixamento social de variáveis, nem sempre as "mulheres tendem a favorecer a forma padrão", ainda que muitos trabalhos sociolinguísticos em zonas urbanas mostrem que as mulheres favorecem as formas consideradas mais prestigiadas.

No processo de mudança linguística aqui analisado, observamos um encaixamento linguístico motivado por variáveis sociais queatuam conjuntamente para que a mudança estrutural seja implementada no português do Rio Grande do Sul, fruto de um processo histórico-linguístico nos moldes de Weinreich, Labov e Herzog (1968). A variação linguística decorrente da inserção da forma inovadora a gente refletiu-se nas diferentes configurações sócio-históricas das classes sociais identificadas nos personagens presentes nas peças de teatro.

A forma inovadora a gente foi impulsionada mais diretamente pelo grupo pertencente à classe baixa, embora os resultados atribuídos ao grupo intermediário na escala social, conforme enfatizado por Labov (1966), sejam também representativos e merecedores de atenção em função dos resultados apresentados. Talvez com a coleta de mais dados, levando-se em conta uma amostra ainda mais representativa, seja possível uma análise ampliada, detalhando-se mais os resultados quanto ao aspecto social, somando-se a isso a constatação de que os resultados também contemplam o proposto por Kroch (1978), de que há uma correlação inversa entre status social e utilização de determinada forma inovadora. Evidencia-se, portanto, que a variação no emprego das formas nós e a gente na posição de sujeito em textos de teatro de autores gaúchos, conforme amostra analisada, pode contribuir efetivamente para o melhor entendimento da atual variação sincrônica, fruto damudança histórica do português brasileiro e das múltiplas relações e implicações entre sincronia/diacronia e variáveis sociais.

\section{Considerações finais}

Os resultados aqui apresentados demonstram que o processo de mudança em torno da inserção e da propagação da forma inovadora a gente expressa no português gaúcho, conforme os dados da amostra trabalhada, intensificou-se a partir da década de 1960, com percentuais para o uso de a gente acima de 50\%, indicando uma mudança em curso. Verificou-se, ainda, que as variáveis sociais gênero, faixa etária e classe social atuaram para que este processo sócio-histórico-linguístico ocorresse, contribuindo para a caracterização das dimensões e dos avanços do processo de mudança, haja vista que os papéis sociais dos personagens foram importantes para o encaixamento social

\footnotetext{
${ }^{15}$ Conforme especificações para as mudanças linguísticas propostas por Labov (1994, p. 78): change from above and change from below.
} 
relacionado ao processo de variação e mudança decorrente da inserção de a gente no português brasileiro.

Este estudo, ao analisar o processo de mudança relacionado à inserção do pronome a gente no português, procurou obter resposta para a questão inicialmente propostas, ou seja, que grupos sociais atuaram nas mudanças? Acreditamos que a análise dos dados abriu frestas que serviram de respostas a muitos questionamentos, embora saibamos que outras questões devam surgir em função dos resultados desta análise, uma vez que as relações envolvendo o processo de mudança de inserção do pronome a gente no português do Brasil são múltiplas, variáveis e dinâmicas.

\section{REFERÊNCIAS}

AMARAL, Amadeu. O dialeto caipira. São Paulo: Anhembi, 1955.

BORBA, L. do R. Alguns aspectos sobre o uso de "nós" e "a gente" em Curitiba. Fragmenta, Curitiba, n. 10, Editora da UFPR, p. 65-76, 1993.

BORGES, Paulo Ricardo Silveira. A gramaticalização de a gente no português brasileiro: análise histórico-social-linguística da fala das comunidades gaúchas de Jaguarão e Pelotas. Tese de Doutorado. Universidade Federal do Rio Grande do Sul, Porto Alegre, RS, 2004.

BORTONI-RICARDO, Stella Maris. Educação em língua materna: sociolinguística em sala de aula. São Paulo: Parábola Editorial, 2009.

ELIZAINCÍN, Adolfo. Tipología y diacronía desde el punto de vista funcional. Atas do IX Congresso Internacional da associação de Linguística e Filologia da América Latina (ALFAL), v. 2, 1993.

GUY, Gregory. Language and social class. Linguistics: The Cambridge Survey, v. 4, 1987.

.Variação e mudança linguística: dimensões sociais. XII Encontro Regional do Projeto Varsul, Curso livre, Universidade Federal do Rio Grande do Sul, Porto Alegre, Brasil, 2001.

GUY, Gregory; HORVATH, Barbara; VONWILLER, Julia; DAISLEY, Elaine. An intonational change in progress in Australian English. Language in society, University Sydney, v. 15, n. 1, p. 23-52, 1986.

HEEMANN, Cláudio. O Teatro de Simões Lopes Neto. In: Teatro completo de Simões Lopes Neto. Porto Alegre: Movimento, 2018.

$\mathrm{KROCH}$, Anthony. Toward a theory of social dialect variation. Language in society, $\mathrm{n}$. 7, 1978.

LABOV, William. The social stratification of English in New York City. Washington D.C.: Center for Applied Linguistics, 1966. 
. Sociolinguistic patterns. Philadelphia: University of Pennsylvania Press, 1972.

. The intersection of sex and social class in the course of linguistic change. Language variation and change, 1990.

. Principles of linguistic change: internal factors. Oxford: Blackwell, 1994.

Principles of linguistic change: social factors.Oxford: Blackwell, 2001.

LOPES, Célia Regina dos Santos. A inserção de "a gente" no quadro pronominal do português: percurso histórico. Tese de Doutorado. UFRJ, Rio de Janeiro, RJ, 1999.

LUCCHESI, Dante. Língua e sociedade partidas: a polarização sociolinguística no Brasil. São Paulo: Contexto, 2015.

MAMBRINI, Ester. Teatro e variação: a colocação pronominal em duas versões de 'A Viúva Pitorra', de Simões Lopes Neto. Dissertação de Mestrado. UFRGS, Porto Alegre, RS,2004.

MATTOS E SILVA, Rosa Virgínia. Caminhos da linguística histórica: ouvir o inaudível. São Paulo: Parábola Editorial, 2008.

MENON, Odete Pereira da Silva. A gente: um processo de gramaticalização. Estudos linguísticos, Anais de Seminários do GEL, Taubaté, 1996.

NARO, Anthony Juluis; SCHERRE, Maria Marta Pereira. Variação e mudança linguística: fluxos e contrafluxos na comunidade de fala. Caderno de Estudos Linguísticos, n. 20, 1991.

NASCENTES, Antenor. O linguajar carioca. 2. ed. Rio de Janeiro: Organização Simões, 1953.

OMENA, Nelise Pires de. A referência variável da primeira pessoa do discurso no plural. In: NARO, Anthony Julius et al. Relatório final de pesquisa: projeto subsídios do projeto censo à educação. Universidade Federal do Rio de Janeiro, Rio de Janeiro, v. 2, 1986.

.As influências sociais na variação entre nós e a gente na função de sujeito. In: OLIVEIRA E SILVA, Giselle Machline; SCHERRE, Maria Marta Pereira. Padrões sociolinguísticos: análise de fenômenos variáveis do português falado na cidade do Rio de Janeiro. Rio de Janeiro: Tempo Brasileiro, 1996.

OMENA, Nelise Pires, BRAGA, Maria Luiza. A gente está se gramaticalizando? In. Variação e Discurso. Rio de Janeiro: Tempo Brasileiro, 1996.

OUSHIRO, Livia. Interação entre Sexo/Gênero e classe social no uso variável da concordância verbal. In: Freitag, Raquel Meister Ko.; Severo, Cristine Gorski (Org). 
Mulheres, Linguagem e Poder - Estudos de Gênero na Sociolinguística Brasileira. São Paulo: Blucher, 2015.

PAIVA, Maria da Conceição de; DUARTE, Maria Eugênia Lamoglia (2003). Mudança linguística: observação no tempo real. In. MOLLICA, Maria Cecília; BRAGA, Maria Luiza. Introdução à sociolinguística. São Paulo: Contexto, 2003.

ROMAINE, Suzanne. Socio-historical linguistics: its status and methodology. Cambridge: Cambridge University Press, 1982.

SEARA, Izabel Christine. A variação do sujeito 'nós' e 'a gente' na fala florianopolitana. Organon, v. 14, n. 28/29, 2000.

WEINREICH, Uriel; LABOV, William.; HERZOG, Marvin. Empirical foundations for a theory of language change. In: LEHMANN, Winfred; MALKIEL, Yakov. (eds.) Directions for historical linguistics. Austin: University of Texas Press, 1968.

ZILLES, Ana Maria Stahl. Grammaticalization of a gente in Brazilian Portuguese. In: JOHNSON, D. E.; SANCHES, T. (eds.). University of Pennsylvania Working Papers in Linguistics (Papers from NWAV 30), v. 8, n. 3, 2002.

Real, apparent, or both? Three types of evidence for a grammaticalization change in progress in Brazilian Portuguese. Philadelphia: VWAV 32, University of Pennsylvania, 2003. 